\title{
Agricultural Contract Farming with Social and Community Economy Adaptation. A Case Study: Hin Tang Village Moo7 Non Khong Sub District, Ban Phang District, KhonKaen Province
}

\author{
Bodee Putsyainunt ${ }^{1}$, Sekson Yongvanit ${ }^{1} \&$ Prasit Kunurat $^{1}$ \\ ${ }^{1}$ Faculty of Humanities and Social Science Faculty, KhonKaen University, KhonKaen, Thailand \\ Correspondence: Sekson Yongvanit, Faculty of Humanities and Social Science Faculty, KhonKaen University, \\ KhonKaen, Thailand. E-mail: sekyon@kku.ac.th
}

Received: December 8, 2013 Accepted: February 17, 2014 Online Published: March 26, 2014

doi:10.5539/ass.v10n8p20

URL: http://dx.doi.org/10.5539/ass.v10n8p20

\begin{abstract}
The purpose of this study is to understand the history of contract farming at Hin Tang Village including the social and economic adaptation of the community with contract farming production. The study employed the concept of community economy. In-depth interviews were conducted through guided questionnaires; with twenty one key informants, that was concerned with the issues in the village as well as each general household's information in the questionnaire, were used to collect data from 121 household representatives. The study was to find a model of agricultural, contract farming which incorporates a collaborative management between agricultural companies and farmers. The companies provided materials such as seeds, fertilizers and insecticides, techniques for cropping each type of plant and methods of marketing management. The farmers were responsible for the investment of their labor, land, equipments and devices. Both the companies and farmer signed a contract in advance that established the terms and conditions related to the number and quality of products the farmers were going to produce and sell to the companies. However, this contract farming yielded an inequity between the companies and the farmers as companies had an advantage over the farmers due to the fact that they controlled the production systems and markets. Although the farmers were at a disadvantage, the companies did not force them into a contract; rather, they compromised to solve the problem as an installment debt by reason of business. However, these farmers had already adapted to their economic and cultural lifestyles and social relationships to live under the contract farming based system.
\end{abstract}

Keywords: agricultural contract farming, capitalist, social and community economy adaptation

\section{Introduction}

The globalization era vastly promotes agri-business and the free market system. This forces lower income class farmers to disengage from the benefits of the free market system and in turn also discourages the farmers from continuing their agricultural lifestyles. This decreases the current labor force and compels them to move into another section of the economy, which is currently seen today. In order to stop this, we can try to improve the agricultural system with the result of increasing the farmers' incomes. However, the major problems now are the lack of funds due to not having access to financial resources, the ineffective or low productivity and un-sustainable market price levels of agricultural product. Consequently these factors lead to the start of agricultural contract farming. By focusing on the effective management in agricultural production and prices that the farmers can trust that they can obtain, the farmers will be able to produce goods at a more effective level and are able to earn a higher income. The companies are able to rely on the quality and quantity of the outputs. The pattern of agricultural contract farming may differ in its style of management and is dependent upon several factors such as the production process, management process and marketing contract agreement. The signing of the marketing contract agreement allows benefits to be distributed to both the farmers and the fund providers which in turn results in a rise of farmers' productivity and would allow them to take more advantage of the benefits in the market.

In Thailand, contract farming had a larger influence upon the production sector after the announcement of the National Economics and Social Development Plan \#6 (1987). The aim of this plan is to increase the global competition within the market by the development in quality and quantity of the output. The results of these 
actions directly affect global demand by using lower cost to compete with other countries. In order for this process to be successful, both the private sector and the government must take action regarding investment and need to support the extension of agriculture within the community. Overall and in chronological order, the process lead to new crops being introduced such as sugar cane, pineapple and eucalyptus etc. By running these policies, the government will be able to set up a project to coordinate with the Agricultural and Cooperative Ministry, financial institutes, farmers in the area and the private sector. The Agricultural and Cooperative Ministry assists the farmers and the private sector when they sign a contract. Moreover, the Agricultural and Cooperative Ministry joins with the financial institutes as the Agricultural and Cooperative Banks Ltd., to provide funds that farmers can take out as loans. The major objectives are to improve the effectiveness of productivity and to decrease the risk of price fluctuation for the farmers. However, this project continuously ran and improved until the National Economics and Social Development Plan \#8 was announced in 1996. Thus contract farming becomes more influential in the agricultural structure because it was used as a tool for National Strategy in the Agricultural Plan. This action allows for development of communities that can lead them to become stronger and be used as a base to improve the country's income. To reduce the poverty in Thailand, the model of contract farming was used as a concept for country-wide development for the future market. Agricultural product insurance and development of the agricultural structure can increase productivity and create more income for the farmers.

Hin Tang village was an example that has used the model of contract farming since 1985, and was part of the National Economic and Social Development Plan \#5. What they did was to grow crops including cucumbers and cantaloupe alongside old major crops such as rice and kenaf. These current harvests were much more suitable for the village's physical state and received ongoing support from the companies in terms of seeds, fertilizers and insecticides. In addition government officials later came to provide agricultural knowledge.

Furthermore, the model of contract farming became the major source of income for the community. Labor transformation from the agriculture sector to other sectors also declined, which allowed local wisdom in the community to enrich and be passed on.

\section{Method}

Research was conducted using qualitative and quantitative methods that reviewed literature and other documents. By using semi-structured guided interviews for the twenty one respondents, each aspect of study; such as the history of the villages, the context of the villages, culture and career groups, were recorded. Questionnaires were distributed to 121 households to collect data by using descriptive analysis methods to obtain results.

\section{Results}

The study showed that contract farming is a new production model of agricultural communities and changes the way of community production to become capitalists, depending on funds and input factors, such as technology etc. from their fund providers.

Although this model is used to improve the productivity in communities to be more effective, farmers must rely on the contract with the fund providers. This follows the findings of Santisombut Y. (2003) that farmers are drawn into the commercial aspects of agricultural production which results in the dependency of the farmers. Moreover, they lose their power to control production, their rights in production output and their status, effectively making them employees rather than landowning farmers as per legal terms. In many cases, this remains unchanged today. This transfers the power of production and marketing terms to the funding companies. The farmer cannot claim or negotiate anything because the original contract states the previous agreement and is binding. Hence, the community must adapt itself to the terms of the economic and social sectors under the circumstance that contract farming is a part of their community.

\subsection{Background of Contract Farming in Hin Tang Village Moo 7Non Khong Sub District, Ban Phang District, KhonKaen Province}

Founded in 1949, the land in Hin Tang village has been occupied by HuaWa villagers. Until now, their agricultural production has been rice and cotton. As Charles F. Keyes (Site in ToSakul, 2009) states, "The way of life in the Northeast was still one of production for consumption and they had little technology to use in their farm." As for this phenomenon, Hin Tang village is little changed, rice is still the main crop produced for consumption in the community, while cotton became the main commercial cash crop. The study discovered that some of the cotton products were shared from household to household in order to produce cloth material. Sadly, its production ceased in 1953 as it was replaced with kenaf and cassava. Since 1985, production of melons, cantaloupes, sweet peppers and tomatoes is being supported by Monsato Ltd. who provided seed, fertilizer, 
insecticide and market price insurance for farmers who participated. That was seen as the first step towards contract farming in the community. However, in those early days, those plants that had been promoted were not produced upon demand, with the exception of tomatoes. This led to a new type of watermelon being introduced to replace the old, only allowing watermelon and tomatoes to be grown on the farms. Later, it was seen that the cultivation of plants in the community had been adjusted only to suit the area's physical and direct market demands as shown in Table 1.

Table 1. Shows the annual crop of Hin Tang village since1949-present

\begin{tabular}{|c|c|c|c|}
\hline Type & Period & Replaced by & Purpose \\
\hline Rice & 1949 & - & For consume \\
\hline Cotton & $1949-53$ & Synthetic Yarn, Kenaf & For consume and sale \\
\hline Galangal & 1949 & - & For consume \\
\hline Lemon grass & 1949 & - & For consume \\
\hline Bird chili & 1949 & - & For consume \\
\hline Cystic Eggplant & 1949 & - & For consume \\
\hline Lettuce & 1949 & - & For sale \\
\hline Morning glory & 1949 & - & For consume \\
\hline Kale & 1949 & - & For consume and sale \\
\hline Cultivated banana & 1949 & - & For consume and sale \\
\hline Chili spur pepper & 1949 & - & For consume \\
\hline Kenaf & $1953-95$ & Cassava, Tomato, Sugar Cane, Water Melon & For sale \\
\hline Cassava & 1977 & - & For sale \\
\hline Coriander & 1983 & - & For sale \\
\hline Chinese cabbage & 1983 & - & For consume \\
\hline Melon & $1985-87$ & Tomato, Water Melon & For sale \\
\hline Cantaloupe & $1985-87$ & Tomato, Water Melon & For consume \\
\hline Tomato & 1985 & - & For contract farming \\
\hline Water Melon & 1987 & - & For contract farming \\
\hline Sugar Cane & 1990 & - & For contract farming \\
\hline Asparagus & 2002 & - & For consume and sale \\
\hline Eucalyptus & 2003 & - & For contract farming \\
\hline
\end{tabular}

The data shown in Table 1 represents the extent of rice and home grown vegetables together with cotton on land since 1949. However, cotton production was reduced as it was replaced by synthetic yarn that was on sale at Don Mong Market. This led to farmers concentrating on new crops such as kenaf in 1953. In 1977, cassava came into the community as a new crop, as well as melon, cantaloupe, sweet pepper and tomato in 1985. For Hin Tang village, this was the first step towards contract farming that led to the halt of kenaf production in 1995. But in 1987, melons, cantaloupes, and sweet peppers were replaced by watermelons. Moreover, it was found that some farmers in the village had been visiting Kanchanaburi Province to harvest sugar cane since 1972, an opportunity that allowed the cultivation of sugar cane. This resulted in the boom of sugar factories in Phu Veing and Nam Phong districts; the interest in sugar and sugar cane related products in 1990 stopped community laborers from going to other provinces for harvesting employment. In the initial period, the sugar cane was grown by individual farmers but in 1997, there were some sugar cane brokers that attempted to contract the community and provided knowledge on sugar cane cultivation for farmers in the village. Because of this, the sugar cane gradually became a part of their cultivation within the contract farming system, which also included eucalyptus as promoted by Phoenix Pulp and Paper Co, Ltd, and the Agricultural Extension Office at Ban Phang district in 2003. But, sadly for these companies, eucalyptus was not as popular with the farmers as the sugar cane, watermelon and tomatoes, since the farmers barely benefited from this new plant, unlike their original crops.

In 1987, studies showed that the model of contract farming became popular in the village because individual farmers could rely on the market's stability and did not face the risk of price fluctuation. Furthermore, this led to farmers using more land for their cultivation and production as such shown in Table 2. 
Table 2. Shows the land used in Hin Tang village at the present time

\begin{tabular}{ll}
\hline Land used & Acres \\
\hline Agricultural & 988.00 \\
Community forest & 114.00 \\
Residential & 30.00 \\
Total & $\mathbf{1 , 1 3 2 . 0 0}$ \\
\hline
\end{tabular}

The findings from Table 2 of land used for Agriculture can be separated by ratio of plants as in Figure 1.

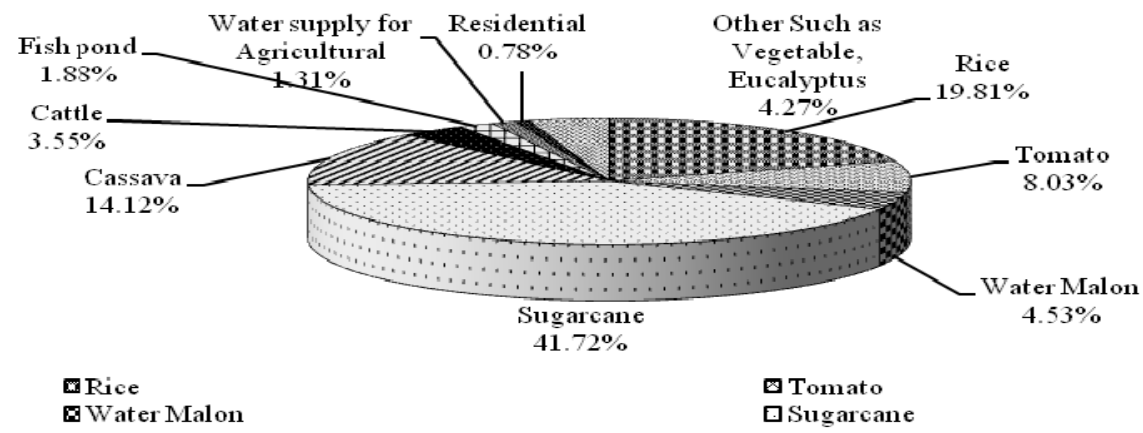

Figure 1. The ratio of land used in Hin Tang village

The results in Figure 1 show that $54.28 \%$ of the total agricultural land was used for contract farming for watermelons, tomatoes, sugar cane-while $43.63 \%$ of total agricultural land was used for other crops or livestock that were unrelated to the contract farming system. $1.31 \%$ of agricultural land being used for agricultural water supply and a meager $0.78 \%$ of land being used by community residents. This data explains that contract farming had a heavy influence in the communities as long as they were related with the concept of the contract farming system. This model has been important in agricultural production since the 1980s. It is a profitable model, which supports small farmers and their communities, leading to higher productivity and better quality of life. (Bello et al., 1998)

The outcomes that occurred in Hin Tang village showed that the contract farming system broke its way into production within the communities, especially when announced by National Economic and Social Development Plan\#6 (1987-1991). This reform took joint action with the government and private sector. As a result, private companies took care of risk of price fluctuation for the farmers, and allowed contract farming to play a greater role in community production.

\subsection{Community Economy Adaptation after Contract Farming Was Established in Hin Tang Village}

Contract farming centered on tomatoes, water melon and sugarcane and took the form of written agreements which specified details of product output and quality. The company relies on the social relationships with the communities such as the Headman of the village, Village Committees or the community leaders to help introduce or invite farmers to join the production. The initial step of the contract is for the headman of the village to allow the surveillance of a suitable area for plants that can be promoted within the community. After they identified their needs for a satisfactory cultivation area, the second step as headman of the village is to invite the farmers to receive knowledge on the plants that are wanted by the companies. The companies not only provide knowledge about the plants, they also explain the contract details and also provide seeds, fertilizer and insecticides. For the farmers that agree to the contracts, all product output will belong to the company. Because the commitments arising from the contracts create changes in the community economies such as Hin Tang village, farmers have to adapt themselves to the contract farming system in the way of production and consumption as can be described below.

\subsubsection{Mode of Community Production}

It was found that after the companies entered into a contract with the farmers in the community they provided material support for their cultivation. The knowledge that companies provided helped them especially to increase productivity and improve product quality. It was found that $70.25 \%$ of households in the community had passed 
the agricultural training especially for tomato, water melon and sugarcane cultivation with the companies but $29.75 \%$ had not. This did not mean that households that had not passed the agricultural training were unable to produce tomatoes, watermelons or sugarcane. If we are to consider the households' experiences in agriculture, the average time spent in the fields was 28 years. Because they have extensive experience in agriculture they can learn quickly by talking with farmers who had passed the training. In that way they can fulfill the conditions of the contract. Interestingly it was observed that of the households that passed the agricultural training, $77.625 \%$ were able to increase their productivity, while $22.35 \%$ were not able to benefit from the training and there are various reasons for that. Some of these farmers claimed that it was not their major career so they did not pay much attention to the sessions, while others claimed that they went into the training because they were persuaded by people whom they respected so they could not refuse. These reasons explain why some farmers were unable to benefit from the knowledge. Another important input factor was the labor force of the community. The results showed that household families were the major labor force for production. They only sometimes used external household labor in their production as shown in Figure 2.

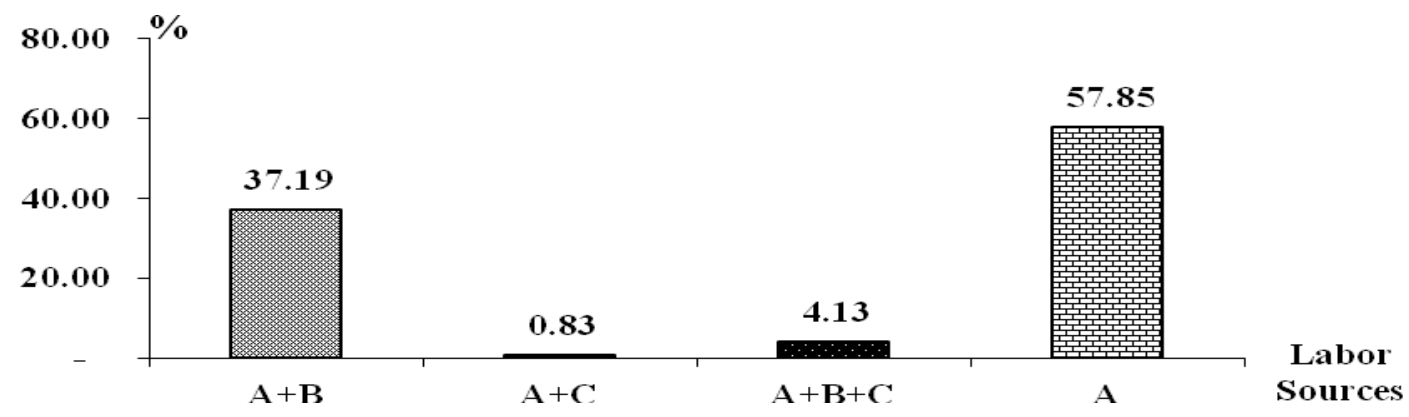

Figure 2. Shows the ratio of agricultural labor demand in Hin Tang village

Remark: A = Household Labor; B = Labor in Hin Tang Village; C = Labor outside Hin Tang Village

The findings in Figure 2 show labor demand in the Hin Tang Village as well as in the agricultural sectors. Household members constitute a major part of the labor force averaging around two to three persons per household. The study results show $57.25 \%$ used only their family labor, $37.19 \%$ shared with internal labor forces in the area, $0.83 \%$ shared only with the external community labor force, and $4.13 \%$ shared with the internal and external labor force for farm production respectively. If we consider the last group, which is $60 \%$ Hin Tang labor force and $40 \%$ external labor force, it can be concluded that family laborers still participate in the community production, while only a few farms use an external labor force. This also highlights that households seek labor in their own village first, but if there is inadequate labor supply in the village they seek outside laborers. Moreover the study found that households are more comfortable working with labor in the village than labor from outside. Normally, households use labor from within their family but sometimes they will use labor from outside depending on the kind of crop, as shown on Table 3.

Table 3. Annual crops for each plant and demand of labor in Hin Tang village production

\begin{tabular}{llll}
\hline Plant & Periods & Source of labor \\
& Crop 1 & Crop 2 & \\
\hline Galangal & Jan.-Dec. & - & Household labor \\
Lemon grass & Jan.-Dec. & - & Household labor \\
Chinese Cabbage & Jan.-Dec. & - & Household labor \\
Asparagus & Jan.-Dec. & - & Household labor \\
Cultivated banana & Jan.-Dec. & - & Household labor \\
Sweet pepper & Nov.-Jan. & - & Household labor \\
Chili spur pepper & Jan.-April & Nov.-Dec. & Household labor \\
Bird chili & Jan.-April & Nov.-Dec. & Household labor \\
Cystic eggplant & Jan.-April & Nov.-Dec. & Household labor \\
Coriander & Jan.-Jun. & Nov.-Dec. & Household labor \\
Lettuce & Jan.-Jun. & Nov.-Dec. & Household labor \\
\hline
\end{tabular}




\begin{tabular}{|c|c|c|c|}
\hline \multirow{2}{*}{ Plant } & \multicolumn{2}{|l|}{ Periods } & \multirow{2}{*}{ Source of labor } \\
\hline & Crop 1 & Crop 2 & \\
\hline Morning glory & Jan.-Jun. & Nov.-Dec. & Household labor \\
\hline Kale & Jan.-Jun. & Nov.-Dec. & Household labor \\
\hline Cassava & Jan.-Mar. & Oct.-Dec. & Household labor, Labor in Hin Tang Village \\
\hline Rice & Jun.-Dec. & - & $\begin{array}{l}\text { Household labor, Labor in Hin Tang Village, } \\
\text { Labor outside Hin Tang Village }\end{array}$ \\
\hline Sugar Cane & May-Dec. & Sep.-April & $\begin{array}{l}\text { Household labor, Labor in Hin Tang Village, } \\
\text { Labor outside Hin Tang Village }\end{array}$ \\
\hline Tomato & $\begin{array}{l}\text { Early } \\
\text { Nov.-Mar. }\end{array}$ & $\begin{array}{l}\text { Last } \\
\text { Nov.-Mar. }\end{array}$ & Household labor, Labor in Hin Tang Village \\
\hline Water Melon & May-Aug. & Aug.-Nov. & Household labor, Labor in Hin Tang Village \\
\hline Eucalyptus & Jan.-Dec. & & Household labor \\
\hline
\end{tabular}

The results from Table 3 shows Hin Tang village farms used labor from outside their families almost all year. This is dependent on each kind of crop that was produced in the area, especially during March. In March, the first crops of cassava are harvested followed by tomatoes. In May, the sugarcane was cultivated which then leads to cassava and rice. In August, the first in line for harvesting was the watermelons, and then after a while, watermelons were harvested yet again. Lastly, the final demand period of labor was from November to December which was when the second crops of tomatoes are cultivated and the cassava, watermelon, sugar cane, and rice are harvested. The sugar cane, tomatoes, and watermelons are the most significant plants for contract farming. The average land used for these crops, prices, and yields are shown on Table 4 below.

Table 4. Shown yield, average price, average land used for contract farming cropped in Hin Tang village

\begin{tabular}{llll}
\hline Plants & $\begin{array}{l}\text { Yield } \\
\text { (Kg./Acre) }\end{array}$ & $\begin{array}{l}\text { Average Price Receive } \\
\text { (Bath/Kg.) }\end{array}$ & $\begin{array}{l}\text { Average Land Used } \\
\text { (Acre) }\end{array}$ \\
\hline Tomato Seed & $0.57-0.67$ & $5,500-6,000$ & 0.3 \\
Water Melon Seed & $0.63-0.94$ & $800-1,200$ & 1.60 \\
Sugar Cane & $300-325$ & $1.20-1.30$ & 10.64 \\
\hline
\end{tabular}

The evidence shown in Table 4 highlights the average land used for tomato crops which is at 0.3 acres, which yielded for seeds at $0.57-0.67 \mathrm{~kg}$ per acre; at which the price received from companies was around 5,500-6,000 Baht per $\mathrm{kg}$. The average land used for watermelon crops was at 1.60 acres, yielding for seeds around 0.63-0.94 $\mathrm{kg}$ per acre at 1,200 Baht per $\mathrm{kg}$. The average land used for sugar cane was at 10.64 acre, yielding $300-325 \mathrm{~kg}$ per acre at the set price of 1.20-1.30 Baht per kg.

Thus, it was seen that after contract farming introduced itself into the communities, the farmers benefited from many effects in terms of production and marketing that belonged to the companies as long as they held the contracts. By this phenomenon, the status of the farmers was changed from the owner of outputs to become employees for the companies as well as being dependent on the companies (Singh, 2005). The same situation was found in the contract farming agreement in Chiang Mai and Lumphun provinces where farmers used seed provided by the companies. At the same time the process of their production and marketing had been kept under tight control (Suebpongsang et al., 2011).

This was what occurred in Hin Tang village. For these reasons, the land owner must accept the change caused by signing their agreement with the companies

\subsubsection{Mode of Community Consumption}

This study found that the start of community dependence on external resources resulted in the expansion of the community. Gravel roads were constructed in 1975 between Hin Tang village and other neighboring villages. It was seen that after gravel roads were constructed, transportation became more convenient and allowed merchants from nearby communities and motorcyclists to gain more access to Hin Tang village. Since 1985, the contract farming system made its way into the village as well as many others in 1987 that led to numerous changes in the way of life within the community due to becoming a major source of income as shown in Figure 3. 


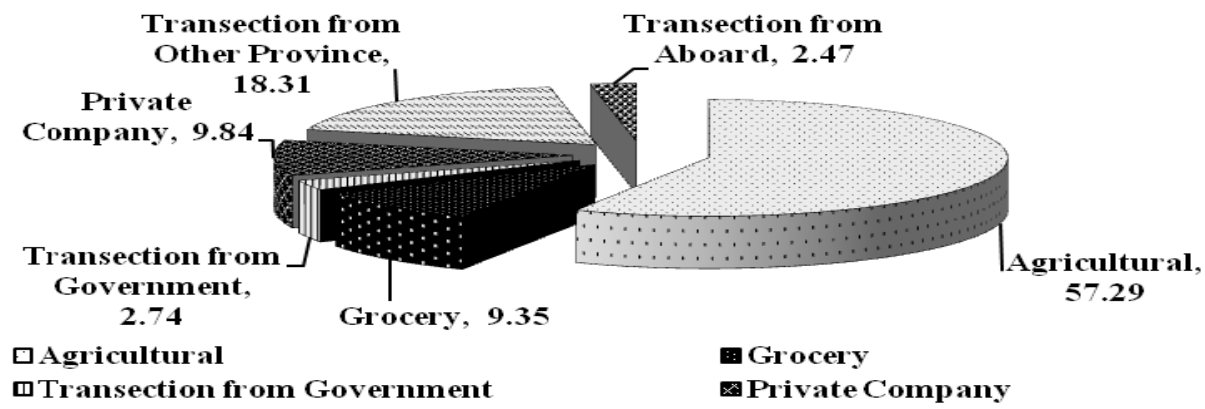

Figure 3. The ratio of Hin Tang income sources

The findings in Figure 3 show that $57.29 \%$ of the total community's incomes were from agriculture while $18.31 \%$ relied on money transactions from family members who worked in another province or outside the area. Not only that, it was also seen that more than $90 \%$ of agricultural income came from contract farming such as tomatoes, watermelons and sugar cane. The data from Figure 3 supported the reasons why contract farming systems are dominating the community's production. The farmers must spend more time in their fields and make more income just enough for their household expenditures as seen in Figure 4.

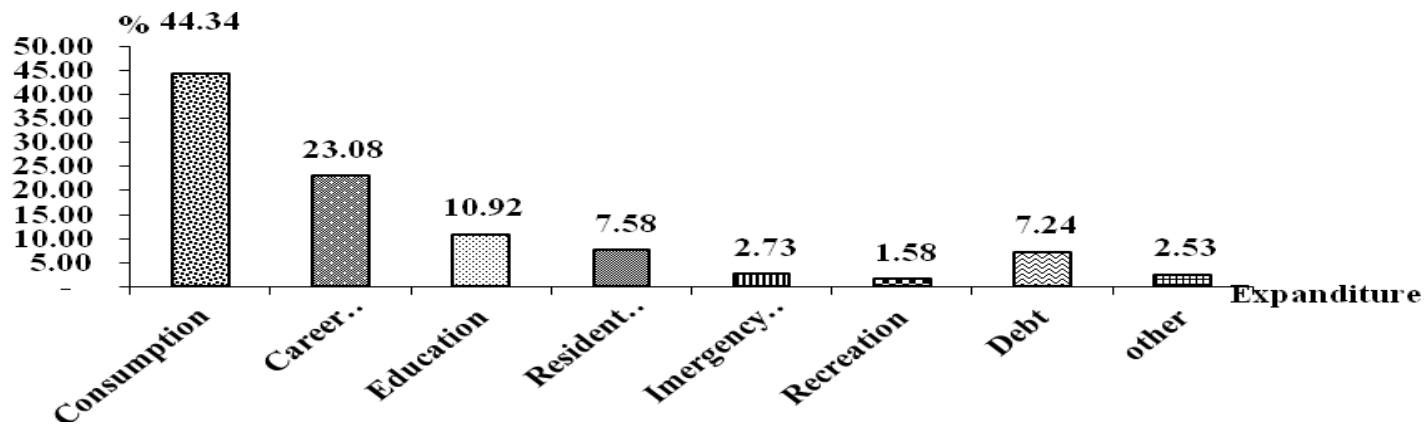

Figure 4. The ratio of Hin Tang village expenditure

Figure 4 reveals the ratio between the community expenditure caused by the contract farming system. This made a deep impact on the community's way of life as they were now more dependent on external resources. The stated $44.34 \%$ comes from the total community expenditures as consumption, investment in careers is at $23.08 \%$, education is at $10.92 \%$, debt payment at $7.24 \%$, and lastly $14.42 \%$ is spent on other necessities. Community investment expenditures on careers are another area of increased community dependence on the outside. It was found that households with community investments used a whopping $83.57 \%$ on external resources, such as fertilizer, insecticides or gasoline, in the investment of agricultural production. Only $16.43 \%$ was labeled as internal resources-seeds, labor, and land for cultivation. Moreover, there was a rise of motorcycles and pickup trucks selling goods such as food and household accessories in the community. For these reasons, it was more convenient for the community to purchase outside goods. However, it made the community more dependent on the outside resources. This led farmers to spend more time on their farms so as to be able to meet the financial demands of those external resources. This goes along the same lines of the recent study carried out by Phothilath, et al. (2013) on contract farming and well-being of households in Nadeang village Xaybouly District Savanakhet province in Laos P.D.R. It was shown that farmers who worked in the system of agriculture contract farming had no time for rest. Moreover, the cost of their production had substantially increased. However, they continued to engage in the contract farming system because it was a main career option available in the village. As stated previously, everything can be seen as connected to the contract farming system, since it has made lots of changes in agricultural production, distribution and consumption in the area-especially the power of marketing and production that have fallen into the hands of companies who own the contracts. As a result, farmers were tuned to be only employees and lost their power to bargain after signing the contracts with the companies as per legal terms. Therefore, communities must adapt themselves to the changes from the ways of capitalism as long as the contract farming systems existed and continued to be the major source of income. 


\subsection{Social Adaptation after Contract Farming Was Established in Hin Tang Village}

This study shows that social adaptation in Hin Tang village, after the contract farming was initiated, helped regular social relationships and participation in the village's activities. It was found that since 1987, after the community had embraced the farming system as a major part of their agricultural production, contract farming compelled farmers to spend more time at their farms which decreased their community participation. However, the households in the community tried to adapt to the change by rotating family members to participate in the activities held by the communities such as major ceremonies like Boon Berk Ban, Song Kran, Boon Ka Tin, as well as agricultural production ceremonies in the village. For these reasons, it is very difficult for farmers to participate in all community activities as long as contract farming is still an important source for community income. However, the results of the interaction of contact farming and village cultures can be seen in Hin Tang village, which has not been completely dominated by external influences; their traditional culture and way of life is still being practiced in the Issan norm as Heed 12 and Klong 14

Another example of social adaptation can be seen in the warm relationship among the people within the community as they go through participating and helping each other in their daily lives. That is seen in community activities such as Boon Berk Ban, Ton Ka Tin. Moreover they formed themselves into a carrier group for supporting their production or helping to solve problems in their communities. Such groups that emerged are Saving Group, Production Saving Group, Fishery Cat Fish Group, Clothing Group, Handmade Group, and the Fertilizer Group. While considering the social change before it actually impacted upon the community, education was largely questioned in 1971 as the villagers set up a community school in Hin Tang village. Their reason in doing this was for their children to have more chances to pursue their education rather than spending their time outside. It was also then in 1973 that the first televisions came into the villages, followed by transportation improvements in 1975, and outer marriages in 1996 that not only greatly changed the community, but also the languages and dressing style. The Thai language became more abundant within the Issan languages as well as the new fashion fad such as jeans came into play. These factors poured into the areas before contract farming approached the villages in 1987 to the present day. However, contract farming in the village still maintained itself as the main factor in the community's social change because it was still the main source of income. As shown on Table 5, the biggest emphasis was social participation.

Table 5. Annual activity in Hin Tang village and villagers participation

\begin{tabular}{lll}
\hline Activities & Objective & VillagersParticipation \\
\hline Jan.: New year & Celebration & Very High \\
Feb.: Boon Kao Chee & Making merit with sticky rice grill Ceremony & Medium \\
Mar.: Boon PhaVed & ThesermonsStory of Buddha. & Very High \\
Apr.: Song kran & Thai new year & Very High \\
May: Boon Bang fai & Play firework asking for rain & Very High \\
Jun.: Boon Berk Ban & Ceremony of villages & Very High \\
Jul.: Kao Pun Sa & Devote the candle & High \\
Aug.: Boon Kao Pa dup din & Devote the good things to people who passed away. & Medium \\
Sept.: Boon Kao Sark & For god of cultivation & Very High \\
Oct.: Aok Pan Sa & Devoted things for monk & High \\
Nov.: Boon Ka Tin & Devoted something for monk & Very High \\
: Loy Krathong & Apologies to the god of river ceremony & Very High \\
Dec.: Boon Khao Kham & Activities of monk to consider them of what they did wrong in & None \\
\hline
\end{tabular}

The findings from Table 5 show that almost all villages participated in the events because it was considered a form of relaxation from the stress and tiredness of working. Examples included the famous celebrations such as Loy Krathong, Songkran, New Year and important religious ceremonies such as Boon Pra Ved and Boon Ka Tin. While other ceremonies were rotated between family members, many came to join in the ceremonies such as Koa Pun sa, Boon Kao Pa dup din and Aok Pan Sa. But regarding the Boon Khao Khan ceremony, no villagers can join in as this ceremony is only for monks.

The study also confirmed that there is a change in the social lifestyle of the community members after contract farming was introduced and this was that the farmers spent more time on their own farm. During vital months in 
May, August and November, pollination was abundant in order for tomatoes and watermelon to grow. Farmers had to be ready for work at 3:00am sharp until 9:00am because during this time, the weather is mild and provides for efficiency in pollination. After that they spent time on their other crops such as rice, vegetables etc. This phenomenon is another reason that supports the contract farming system due to the farmers spending more time in their fields although they have fewer rest periods. Other factors, unrelated to the contract farming, such as education levels which took place as well as the transportation movement while some community traditions disappeared, for instance illness treatment such as the Pee Fa Dance in 1997. Villagers have more confidence in treatments that use modern medicine rather than illness treatment by Pee Fa Dance. But for the contract farming, it caused changes in the community's local knowledge which began to decrease production of clothing and woven products. It was found that they were still being produced by the older generation who were more than sixty five years old, while the new generation workers did not produce them as the benefit in terms of income was not attractive compared with income received from contract farming. Although they were able to learn from their parents, how to weave, they lacked the local knowledge in order to do as in the future as they lacked a person who was skilled in Brahma after 2011. It was found that this was because they had not much time to participate in community activities because they must spend their time at work on their farms.

From the previously stated points of view, it was seen that after the contract farming system arrived in the community, they adjusted themselves by maintaining a community relationship so they could get along with the community economy. Although, in the present day, the households don't join in as many activities as they did previously, they still rotate a family member to participate every now and then to avoid tension in the relationship between the people in the community and to maintain their current life style with Issan traditions as Heed12, Klong14. Not only that, but they also beneficially form career groups to assist in their production problems and make extra income for their family. This can be considered as community identification under the existing social structure. It was apparently shown that there was not only one party that was powerful, but the two parties needed to balance their power under the agreement between companies and community. The companies hold all the contracts and have the power to punish farmers if they broke agreements. However, the results found that they did not follow the contract strictly and could be flexible in terms of debt relief or changes in the rate of price for product purchased. Luckily this reduces the conflicts between firms and farmers because companies are quite dependent upon the farmers due to the fact that land and labor are important factors to the industry sectors. If they have any problems within any of their lines in the process, it severely affects the industrial sectors, which tends to lead other companies to form contracts with the same village. For this reason, it is a safer idea for famers to officially sign the contracts so that the communities undergo social adaptations that not only maintain relationships between people but also with the economy sectors to reap the benefits between farmers and the companies. That is the considered view of Popkin (1979) in the context of economic and social transitions in peasant communities to the capitalist system. "Peasants had their own way to handle problems, by maintaining for their benefit the authority to negotiate. This is acceptable due to the benefits going towards both parties. The farmers are not only protected, but their products as well as with the inclusion of sufficiency in their consumptions; thus increasing their productivity and benefits."

\section{Conclusions}

Contract farming has benefited and changed the way of production in Hin Tang village. They have produced commercial products and this has become the main income source for the community. Moreover, they have led farmers towards being more dependent on the external resources in terms of productions and marketing and have become more integrated with the outside world. Although contract farming is the base model of production in the capitalist system, it does not make much of an indent in the social structures of communities. As seen presently, the traditions of communities are still continuing, but they have evolved to be more suitable with change of land used in cultivation and household labor within the production process and this is the distinguishing characteristic of the economy and social farmers. But sometimes they use labor from outside of their family for cropping and harvesting seasons. Although the contract farming system is a modern agriculture practice using new technology, standardizing the production process and is an exact way to produce (Swain, 2009) but they are not able to make many changes in the community production mode when comparing with the capitalist system. Farmers still have the freedom to produce their desired plant or crop. Farmers still grow rice, vegetables and livestock for their subsistence and use the surplus to make extra income for their families. The community's traditional production still continues today, with a guarantee for the community's food supply. For these reasons, the contract farming system became the model for the main source of income for the community, but it did not change any sector in the traditional sense of life but followed the flow as seen in Hin Tang village. The most fundamental thing is that the farmers have the freedom of the usage of their crops as well as not producing more than their labor can afford. 
As Nartsupa C. (1998) states "Capitalism has not revolutionized the way of production, trade and community seriously, nor has it replaced the communities traditional livelihood" as shown on Hin Tang village as today.

In summary, contract farming has changed the way of production within the Hin Tang village in order for a more commercial production. They led the dependence towards external resources in terms of production and marketing. While the contract farming system is a way of production within the capitalist formations, they have not made much change towards the sectors of social structures in the areas. As recently explained, various amounts of product outputs in the communities are non-related with the farming system in which they do not include family from the outside, rather a friendly characteristic of employment such as a 'friend' instead of an employer to an employee. Another reason the model of contract farming is still performed with smaller farmers is in an attempt not to change them into firms or anything industrial. This means that the community cannot leave their traditions behind. Although contract farming remained the main source of income, farmers still have the freedom to choose what to grow and how to grow it. For the social adaptation, although contract farming caused a reduction in community participation or some loss of local wisdom, there was rotation within family members to participate in community activities. To avoid such tension within the people in the community, they promote the preservation of their local wisdom, such as traditional cloth making (fibers) and weaving which they have learnt and passed through generations from their ancestors. Although they were not produced for sale, as in previous times, they were produced for use in their households or for community activities. With these points it may confirm that contract farming was not making changes in their of life and social issues of the community. Moreover, it was found that companies were not strict in the terms of their contracts and did not concentrate on changing the community's social life. Because the companies are still quite dependent upon inputs such as the labor force and the land for cultivation, they will try their best to maintain the relationships between the people as well as to integrate many benefits both for the community and for the companies-including economic and social, running parallel to capitalism.

\section{References}

Nartsupa, C. (1998). Culture of Thai Village. Bankok: Sangsan Publishing Ltd.

Phothilath et al. (2013). Contract farming and Well-Being of households: A case study of sugarcane field, Nadeang village, Xaybouly district, Savannakhet Province, Laos P.D.R. The $9^{\text {th }}$ International Conference on Humanities and Social Sciences $14^{\text {th }}-15^{\text {th }}$ November 2013, KhonKaen University, Thailand.

Popkin, \& Samuel. (1979). The Rational Peasant: The political economy of rural society in Vietnam. Berkeley: University of California Press.

Santisombut, Y. (2003). Flexible peasants: Conceptualizing the Third World's rural types. Chingmai: Design Publishing Ltd.

Singh, S. (2005). Contract Farming System in Thailand. Economic and Political Weekly.

Suebpongsang et al. (2011). Contract Farming System: Agreements, Farmer's Preferences, Pros and Cons from Stakeholders' views in Chiang Mai and Lamphun Provinces. The $7^{\text {th }}$ National Agricultural System Conference. $8^{\text {th }}-10^{\text {th }}$ Aught 2011, Takasila Hotel, Mahasarakarm, Thailand.

Swain, B. B. (2009). Contract Farming and Agricultural Development: A Case Study of Orissa. The Icfai University Journal of Agricultural Economic, VI(1), 57.

Tosakul, R. (2009). Regionalism in Northeastern Thailand. Social and Humanities Faculty Bankok: Thamasat University.

Walden, B., Shea, C., \& Likheng, P. (1998). A Siamese tragedy: Development \& disintegration in Modern Thailand. Oakand Calif: Food First Book Press.

\section{Copyrights}

Copyright for this article is retained by the author(s), with first publication rights granted to the journal.

This is an open-access article distributed under the terms and conditions of the Creative Commons Attribution license (http://creativecommons.org/licenses/by/3.0/). 